\title{
AC 2010-1506: INSTITUTIONAL OBSTACLES TO INTEGRATING ETHICS INTO THE CURRICULUM AND STRATEGIES FOR OVERCOMING THEM
}

\section{Kelley Walczak, University of Michigan}

Kelley Walczak is a doctoral student in the Center for the Study of Higher and Postsecondary Education at the University of Michigan. Her research interests include student development, campus culture, learning styles, and qualitative methodology. She is currently a member of the Association for the Study of Higher Education, American Educational Research Association, and ACPA-College Student Educators International.

\section{Cynthia Finelli, University of Michigan}

Cynthia Finelli, Ph.D., is Director of the Center for Research and Learning North at U-M. She actively pursues research in engineering education and assists other faculty in their scholarly projects. She also is past Chair of the Educational Research and Methods Division of American Society of Engineering Education and guest co-editor for a special issue of the International Journal of Engineering Education on applications of engineering education research.

\section{Matthew Holsapple, University of Michigan}

Matthew A. Holsapple is a doctoral candidate at the Center for the Study of Higher and Postsecondary Education at the University of Michigan. His research interests include the impact of educational experiences on student moral development and personal and social responsibility, professional ethics education, college student outcomes assessment, and quasi-experimental research design in higher education. He is currently a member of the American Education Research Association, Association for the Study of Higher Education, and NASPA-Student Affairs Administrators in Higher Education.

\section{Janel Sutkus, Carnegie Mellon University}

Janel A. Sutkus, Ph.D., is Director of Institutional Research and Analysis at Carnegie Mellon University, where she is responsible for analysis and assessment of all administrative and academic functions. Her work focuses on student engagement, enrollment prediction, modeling responses to institutional financial aid, and developing an integrated model of student persistence within Carnegie Mellon's six undergraduate colleges. She is currently a member of ASEE, the Association for Institutional Research, and the Association for the Study of Higher Education.

\section{Trevor Harding, California Polytechnic State University}

Trevor Harding, Ph.D., is Professor and Chair of Materials Engineering at California Poly, where he teaches courses in engineering design from a materials perspective. His research focuses on educational outcomes associated with service learning and project-based learning with a particular emphasis on ethics education. He is also PI on several projects investigating the degradation of biomedical materials in physiological environments. Dr. Harding is Associate Editor of the journal Advances in Engineering Education, chair of the Materials Division of ASEE, and program chair of the Educational Research and Methods Division of ASEE.

\section{Donald Carpenter, Lawrence Technological University}

Donald Carpenter, Ph.D., P.E., LEED AP is an Associate Professor of Civil Engineering. He is actively involved in ASEE, is a Kern Fellow for Entrepreneurial Education, and serves as Director of Assessment for Lawrence Tech. His research interests involve academic integrity, assessment of student learning, and water resources. 


\title{
Institutional Obstacles to Integrating Ethics into the Curriculum and Strategies for Overcoming Them
}

\begin{abstract}
Several national reports emphasize the importance of providing undergraduate engineering students with effective ethics education, and most engineering faculty and administrators agree that ethics is an important aspect of engineering undergraduate education. However, there are many obstacles to integrating ethics into the curriculum. This study investigated these obstacles at 18 diverse institutions and found five common themes: 1) the curriculum is already full, and there is little room for ethics education, 2) faculty lack adequate training for teaching ethics 3) there are too few incentives to incorporate ethics into the curriculum, 4) policies about academic dishonesty are inconsistent, and 5) institutional growth is taxing existing resources. This study concludes with recommendations for overcoming these obstacles.
\end{abstract}

\section{Introduction}

Recent, high profile cases such as the interstate bridge collapse in Minneapolis, levee failures in New Orleans, and steering and braking failures in Toyota automobiles have elevated ethics in engineering to national and international attention. These cases stress the significance of ethical responsibility in the engineering profession and emphasize the need to educate engineering students about their professional and ethical obligations.

Several national reports emphasize the importance of providing undergraduate engineering students with effective ethics education. Reports from the National Academy of Engineering (NAE) conclude engineers need to be trained to recognize their professional responsibilities and the ethical implications of their work ${ }^{12,13}$. In addition, most engineering faculty and administrators agree that ethics is an important aspect of engineering undergraduate education. In fact, the Accreditation Board for Engineering and Technology (ABET) includes ethical and professional responsibility as one of its program objectives for accreditation of engineering programs ${ }^{5}$, and the professional codes for most national engineering societies include tenets related to ethical responsibility as well ${ }^{1,14}$.

Despite the compelling evidence and accreditation requirements to include ethics in engineering education, many engineering programs struggle to incorporate ethics into the curriculum. These difficulties stem from both institutional and personal contexts, but all have an impact on the ethics curriculum and education of engineering undergraduates. Because of the importance of developing ethical engineers, it is critical to identify these obstacles so they can be addressed by engineering programs. This study investigates these obstacles and suggests ways to overcome them.

\section{Literature Review}

The importance of developing ethical engineers highlights the need to integrate ethics into engineering education. Harris, Davis, Pritchard, and Rabins ${ }^{7}$ identify nine purposes of engineering education which Newberry ${ }^{15}$ classifies into three categories: particular knowledge, intellectual engagement, and emotional engagement. Newberry argues that particular knowledge, 
or the awareness of professional ethical standards, is the easiest objective to obtain and often the highest level of ethics education implemented in the undergraduate curriculum. He suggests that intellectual engagement, or the knowledge of how to make ethical decisions, is important and necessary for educating engineers who will be capable of sound and ethical decisions as professionals. Finally, emotional engagement, or the desire to behave ethically, is difficult to measure as an outcome within the education curriculum but is ultimately a key component to ensuring students behave and act in an ethical manner as professionals.

Current research on ethics education in engineering highlights the diversity of both content and delivery of the ethics curriculum ${ }^{7,8}$. Institutions utilize both separate ethics courses and technical courses with integrated ethical content to deliver ethics instruction 9 . The most common approaches to teaching ethics are case studies and professional engineering codes of ethics ${ }^{7,8,11}$. Others have argued professional codes and case studies do not adequately address the social responsibility inherent to the field of engineering ${ }^{3,10}$. Thus, some institutions have implemented service learning or other experiential education as an integral part of ethics education ${ }^{8,9}$.

Despite the diverse methods of delivery and the varied content of the ethics curriculum, faculty face obstacles to integrating ethics into the curriculum. These obstacles include personal factors, such as students' levels of maturity and faculty attitudes towards teaching ethics, as well as systemic barriers, such as inadequate ethical training in the faculty's own education ${ }^{15}$. These systemic barriers can interfere with the ability to incorporate ethics into the curriculum, and thus potentially hinder students' ethical development. Therefore, it is important to recognize these obstacles and develop ways to overcome them.

\section{Conceptual Framework}

The overall research project is guided by a conceptual model of ethical development, as shown in Figure 1. This model uses the input-environment-output framework described by Astin for the purposes of assessment in higher education ${ }^{2}$. In our model, ethical development (i.e., output) is comprised of three components: knowledge of ethics, ethical reasoning, and ethical behavior that mirror the objectives posited by Harris et al. ${ }^{7}$, and summarized by Newberry ${ }^{15}$. Knowledge of ethics refers to understanding the ethical and professional responsibilities of engineers, such as professional codes of conduct. Ethical reasoning is the ability to recognize ethical problems and generate ethical solutions in a professional context. Finally, ethical behavior involves following through on ethical intentions and ethical solutions.

We posit an engineering student's ethical development is influenced by four aspects: student characteristics (i.e., inputs), curricular experiences, co-curricular experiences, and institutional culture (i.e., environment). Student characteristics include demographic variables and individual attributes, such as academic motivation. Curricular experiences include those experiences occurring within a formal academic program whereas co-curricular experiences refer to student experiences outside of the formal academic program, such as participation in student organizations. Institutional culture refers to the collective practices, traditions, social norms, values, and ideals of each institution. 


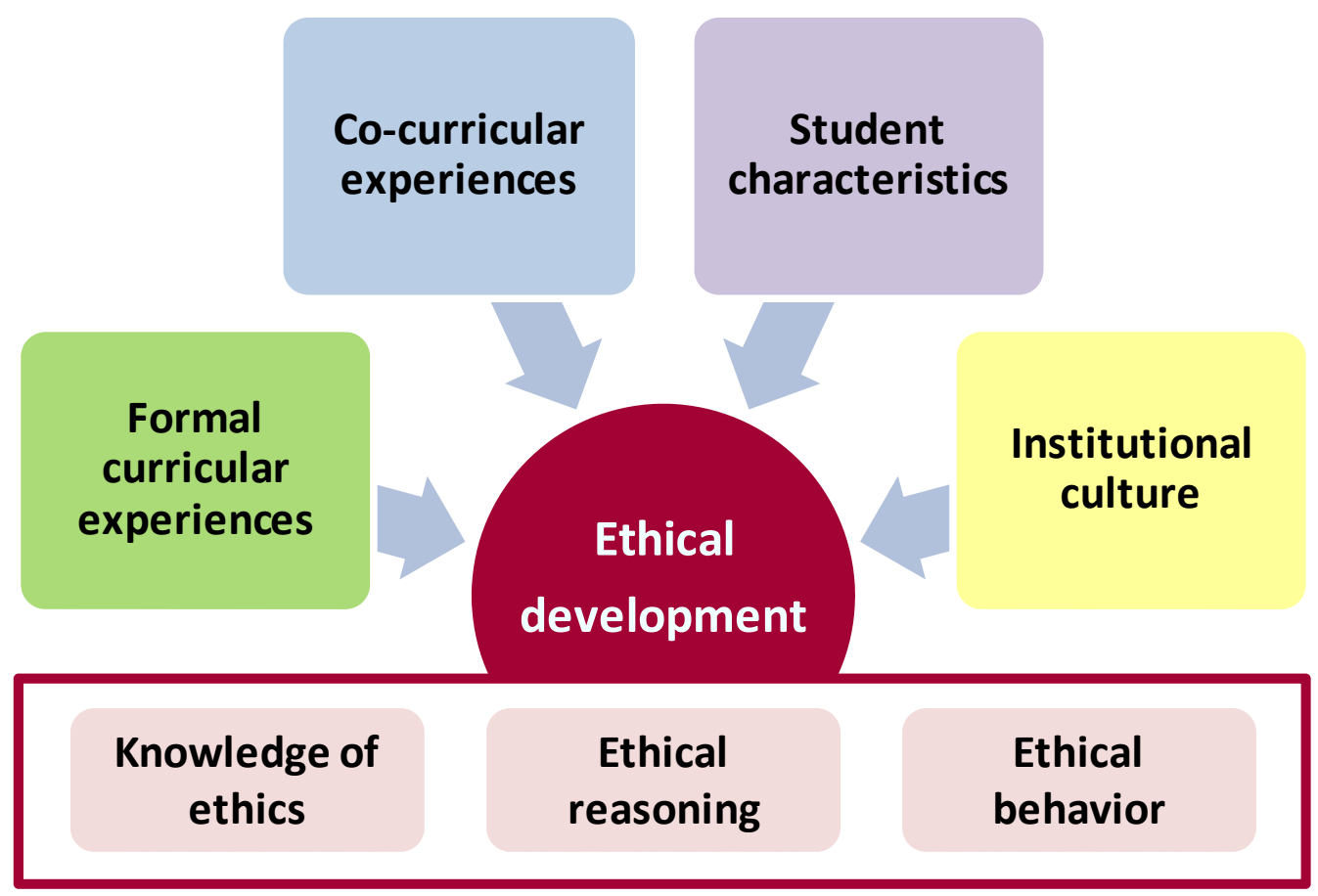

Figure 1. Conceptual Model of the Ethical Development of Engineering Undergraduates

This study looks at the disconnect between the "environment" components and ethical development by investigating the obstacles to ethical development. Specifically, this research focuses on the aspects of institutional culture which may inhibit the integration of ethics education into the curriculum by uncovering the institutional barriers to ethical development. We seek to answer the following research questions:

1. What institutional barriers do faculty and administrators perceive in incorporating ethics into undergraduate engineering education?

2. How can these barriers be overcome?

\section{Methodology}

As part of a multi-year, NSF-funded study of ethical decision making in engineering, we conducted campus visits to 18 diverse engineering colleges and universities over a three year period. Institutions were divided by Carnegie classification, and then those institutions with the greatest number of civil, mechanical, and electrical engineering students enrolled were selected to participate in this study, with some modifications made to maximize geographical diversity.

The purpose of the campus visits was to gain an understanding of individual institutional culture and campus practices that affect ethical development in undergraduate engineering students. The information obtained through the campus visits will be used to develop the Survey of Engineering Ethical Development (SEED) instrument that will be administered to approximately 4000 undergraduate engineering students at 20 diverse institutions in Spring 2010. The qualitative data gathered through the campus visits will be analyzed independently and in conjunction with the SEED results. In addition, each participating institution will receive an 
individual campus report that includes both the results of the survey and a rich description of its institutional culture and campus practices that positively and negatively affect ethical development. This report will address practices the institution does well in addition to identifying areas for improvement.

We received IRB approval from each campus prior to our visit. Each campus visit included a ninety minute focus group with engineering students from a variety of disciplines and a ninety minute focus group with faculty, as well as sixty minute individual interviews with a relevant academic administrator and a student services administrator. Students were selected using a randomly generated list and recruited to participate via email. A campus liaison assisted with the recruitment of faculty and administrators who were selected due to their knowledge of ethics in the curriculum or because of their involvement with ethics education.

Each focus group participant completed a demographic questionnaire prior to the start of the focus group, and we used a semi-structured protocol for both focus groups and administrator interviews. Over the three years of data collection, four different sets of protocols were used ${ }^{16}$. Following the constant comparison method of Grounded Theory research, the protocols evolved as the ongoing analyses revealed new issues and concerns to address ${ }^{4}$. However, all of the protocols included questions to uncover (1) perceptions of ethics education, including curricular and co-curricular activities that may influence ethical development, and (2) aspects of institutional culture believed to affect ethical development. Administrators were specifically asked to discuss any barriers they perceived to integrating ethics into engineering education as part of their discussion of institutional culture. This phenomenological approach to research, which seeks to understand the subjective experiences and perceptions of participants, was necessary to capture the diverse experiences of students, faculty, and administrators across institutional types ${ }^{4}$. In addition, some elements of institutional culture, such as the values and social norms, were only brought to the attention of an outside researcher through participants' perceptions and descriptions.

For this study, faculty $(\mathrm{n}=110)$ and administrator $(\mathrm{n}=37$; one campus had three administrator interviews instead of two) responses related to integrating ethics into the curriculum were analyzed and compared. Students were omitted from the analyses because they were not involved in the development or the implementation of the curriculum. Eighty-four percent of the focus group participants were male, and ninety-one percent were white. These numbers differ from national averages (eighty-eight percent male, seventy percent white ${ }^{6}$ ), but the variation is not surprising given the purposive, rather than random sampling of participants. Approximately one fourth of participants were not on the tenure track, but fifty-seven percent of participants were tenured. Almost three-quarters of the participants held non-teaching responsibilities within the college of engineering such as advising, research, and/or leadership positions.

Data from the eighteen faculty focus groups and thirty-seven administrator interviews were transcribed, and we used NVivo 8.0 qualitative coding software to organize the data analysis. We applied methods based in Grounded Theory research ${ }^{4}$ to code and analyze the data. First, each transcript was read line-by-line and coded based on emerging themes. We used the method of open coding to identify and capture concepts and ideas from the raw data. As new concepts emerged, we returned to previously coded transcripts to check for the newly identified concepts. 
From this first round of open-coding, over forty themes emerged, including "obstacles to ethical development." We subsequently used axial-coding to identify conditions, contexts, and consequences of these obstacles to integrating ethics education into the curriculum. We found over 170 examples of "obstacles," and through the process of axial coding, we grouped these examples by context and developed a category of "institutional culture." This category contained more than fifty examples from the eighteen institutions, which described institutional obstacles to students' ethical development that had been identified in the faculty focus groups and administrator interviews. Finally, we further analyzed these examples to understand how these institutional obstacles affected the integration of ethics into the curriculum. Throughout the coding and analysis process, we also identified ways in which campuses have worked (or could work) to overcome these obstacles.

\section{Obstacles to Ethics Education}

Analyses of the examples of institutional barriers organized into five categories. These obstacles were identified by faculty and administrators across institutions and institutional types, but not every obstacle was cited by every institution. Due to the semi-structured nature of the protocols and different interviewing styles of each member of the research team, the topic of obstacles was explored to varying degrees at each point of data collection. In addition, the number of faculty participating in the focus group varied from institution to institution. These inconsistencies may have contributed to the variation in number of examples describing each theme. Though the number of institutions that identified each type of barrier varied and therefore limited the strength of inference about each barrier, the range of institutional barriers captured through this study provides a broad picture of institutional obstacles. This broad angle offers other institutions a range of possibilities to consider and explore when addressing their own obstacles toward implementing ethics into the curriculum.

Faculty and administrators perceived the following obstacles, in order of most frequently to least frequently cited:

1) The curriculum is already full, and there is little room for ethics education,

2) Faculty lack adequate training for teaching ethics,

3) There are too few incentives to incorporate ethics into the curriculum,

4) Policies about academic dishonesty are inconsistent, and

5) Institutional growth is taxing existing resources.

Both faculty and administrators noted that these obstacles not only provided challenges to teaching ethics, but they also deterred faculty from incorporating ethics into the curriculum.

Obstacle 1: The curriculum is already full, and there is little room for ethics education

Faculty and administrators almost universally expressed concern about finding room in the curriculum to teach ethics. As one academic affairs administrator simply stated,

We just don't have that kind of space to formally [teach ethics] in the curriculum... The technical material has to be presented and we are constrained to the number of hours we can require [students] to take.

The full curriculum and limited room referred to both restrictions on numbers of required courses as well as the breadth of technical material covered in each class. This obstacle was further 
complicated by state or institutional mandates that specified a maximum number of hours an institution or a department could require for a degree. Some participants advocated adding an ethics-specific course as the best option for their institution or program, but they questioned what course could be sacrificed in order to make room for an ethics course. Other participants supported integrating ethics education into the existing curriculum, but they noted that faculty members already face difficult decisions about what technical material to cover so designating even one lecture to cover ethics meant having to forgo additional technical material. Many faculty expressed reluctance to change the course content to incorporate ethics, and a few wondered if it was ethical to reduce technical content in a lower division course that may be needed by students in advanced courses, simply to make room for ethics education.

Obstacle 2: Faculty lack adequate training for teaching ethics

In addition to a full curriculum, participants from ten institutions expressed concerns about teaching ethics. Several faculty participants stated they did not have expertise in ethics and therefore were reluctant to teach the material. As one faculty member stated:

We are not trained to teach ethics, OK? We are not philosophers; we are...just like anyone else in this world, we are faced with ethical dilemmas in our lives. Really teaching ethics here, in general at universities, I would say, engineering faculty are not that qualified.[...] I mean, if I go and talk about IEEE Code of Ethics, I don't know how to teach that. I mean, if there is anything other than I have been teaching electrical engineering all my life and, hey, there are things that are legal, illegal-they are clear. But ethical issues are not clear, they are borderline.

Many faculty and administrators expressed hesitation about teaching material they were not trained to teach, and they thought ethicists should be the ones teaching ethics. Others expressed a willingness to try to incorporate ethics into their courses, but they admitted having no idea as to where to begin. In contrast, a few faculty members had collaborated with philosophy professors or teaching and learning centers on their campuses, and those faculty found that this support gave them direction and support to tackle the challenge of incorporating ethics into their courses.

Additionally, some faculty and administrators interpreted teaching ethics as directing students what to think or how to behave. Some participants attributed this reluctance as not wanting to offend students' political, religious, or moral values, but others admitted feeling personally challenged by ethical issues. As the faculty member above noted, ethical issues are not clear, and participants found it difficult to address these issues when they were also unsure of the "right" answer. Due to the faculty discomfort combined with the ambiguity of the material, a few faculty participants expressed concern as to whether ethics could actually be taught.

Obstacle 3: There are too few incentives to incorporate ethics into the curriculum

Due to the full curriculum and the overall lack of training on how to teach ethics, faculty members were already reluctant to make adjustments to their courses. However, this reluctance was magnified because they had few incentives to make changes. Faculty expressed concern, and sometimes resentment, that they were expected to make changes to their courses or to implement new pedagogies, and yet they received no incentive to do so. A few participants stated they would like to make changes, but their teaching, research, and service responsibilities left them with little time to be creative. Another participant found a conference about engineering and 
ethics he wanted to attend but ultimately did not because he would have to pay for the conference out-of-pocket. Ethics is required to be a part of engineering education, yet faculty and administrators noted that they received few incentives to make changes to their courses.

In some cases, faculty may be discouraged from changing their course or taking risks in the classroom. As one administrator noted:

[Faculty] are not rewarded for [talking about ethical behavior] and they should be. It should be part of the reward system for faculty, to help students be good people as well as just be good scholars... The promotion and tenure guidelines for the teaching component [are] weighted heavily, and I think almost primarily, by student evaluations. So [faculty] can't...they believe that they can't really go out on a limb and push students because they'll get negative teaching evaluations.

At this institution and others like it, the emphasis on teaching and the use of student evaluations as the assessment of teaching in the promotion and tenure process actually discouraged faculty from challenging students to think beyond what is familiar and comfortable. In addition, when combined with the aforementioned curricular constraints and the discomfort with teaching ethical material, faculty had few incentives to make changes in order to incorporate ethics into the curriculum.

Obstacle 4: Policies about academic dishonesty are inconsistent

Faculty from three institutions recognized that students experience confusion regarding academic policies, and these policies influenced students' ethical behavior. This confusion occurred both from inconsistent policies and inconsistent enforcement. Faculty often had expectations for behavior from students, but sometimes encountered situations when these expectations had not been communicated to the students. For example, as one professor stated:

I was working at [institution's satellite campus] and they don't have an honor code system in place and so it was interesting to deal with what we [at the home institution] would consider very strong violations of the honor code. How do we treat those students? What do we do?

In this instance, the faculty member encountered unethical behavior from students, but was unsure of how to proceed because the academic policy had not been explained to the students. Under circumstances in which the academic policy or enforcement of the policy was inconsistent, faculty and administrators questioned whether it was fair to discipline students who were unaware of the honor code, but also wondered what message was sent to both offending students and the other students if the offending students were not disciplined.

In addition to confusion around academic policies and honor codes, faculty and administrators also recognized that students were often confused about group work and collaboration with other students. For example, students perhaps believed they were acting ethically when they worked together on homework, but each faculty member and each course had different guidelines about working together which ultimately caused problems. As one faculty member noted:

In many cases, it's not...consistent. And some [faculty] or some courses may allow homework to be done in groups and turned in as a group. Some homework is allowed to be done in pairs and turned in as pairs; or you turn in separate homework assignments 
and you say who you worked with; and some classes are only individual work. And so it's almost like mixed messages.

Despite intentions to behave ethically, the faculty and administrator participants recognized that students were often confused or ignorant about what behavior constituted cheating and faculty were often inconsistent in the enforcement of the policies. Administrators noted that some faculty regularly referred students for perceived academic dishonesty, while other faculty never reported students. Administrators believed these discrepancies were due to differences in how faculty defined cheating, as well as how diligent faculty were in discouraging unethical behavior. In addition, faculty admitted that following through on every instance of cheating or unethical behavior often required too much time which also led to inconsistencies in frequencies of reporting unethical behaviors and enforcing policies around academic integrity.

Obstacle 5: Institutional growth is taxing existing resources

The recent movement to increase participation in science and engineering has led to rapid growth in the student population for some institutions. Though this growth has advantages, a few of the institutions in the study were unprepared for the effects of a larger student body. Though several institutions mentioned positive and negative effects of institutional growth, faculty and administrators from one institution specifically noted that the institution's rapid growth had altered the delivery of ethics in the engineering curriculum. For example, an administrator described an ethics seminar implemented at his institution five years earlier that had "worked exceedingly well," but noted:

...except we've grown so much in size, we've been growing seven to ten percent a yearactually, this year we grew by eleven percent-so we've doubled in size in that period of time, basically, and so that very intimate kind of setting we just couldn't orchestrate [anymore] for a variety of reasons.

Classes had grown too large to have the same intimate discussions about ethical issues that the faculty enjoyed when classes were smaller. In addition, participants at the other institutions noted they had to teach additional sections of courses to accommodate the growing student body. Participants noticed they had less time to spend with students, and had fewer personal relationships and mentorships with students. Consequently, participants had fewer opportunities to discuss ethical issues and role model positive ethical behavior with their students.

\section{Recommendations}

Based upon these analyses, we recommend several ways these obstacles may be overcome:

1) Integrate curricular and co-curricular activities,

2) Collaborate across disciplines and divisions to create content around ethics education,

3) Offer incentives to faculty for training or curricular innovation, and

4) Present consistent policies among faculty and staff regarding academic dishonesty.

Recommendation 1: Integrate curricular and co-curricular activities

Faculty and administrators recognized that students often engage in out-of-class activities that provide opportunities for ethical development yet also admitted they did little to encourage or promote these opportunities. Student organizations are one avenue to integrate ethics into 
engineering education without further taxing the curriculum. For example, many of the professional student organizations (e.g., American Society of Civil Engineers) brought in guest speakers from industry, and these speakers offered a wealth of real-life ethical dilemmas and case studies to be shared and discussed with students. These co-curricular activities could be brought back to the class through group discussion of the issue presented or short reflection papers.

In addition, many students already participate in community service activities, but these activities are rarely tied to their engineering education. However, service-learning provides an opportunity to embed ethics into the curriculum. A faculty participant noted that service learning projects provided "a way that we can teach our students the knowledge, the content knowledge, that they need with the context [through] socially relevant projects, and the meaning behind engineering." Service learning offers students the opportunity to integrate an activity they are already participating in (i.e., community service) with their coursework in order to promote ethical development, particularly the ethical behavior component. Service learning also offers experiential learning during which a student may encounter an ethical issue. These real-world examples can also be brought to the class through discussions or reflection papers, similar to guest speakers.

These co-curricular experiences also address the components of ethical development in our model (Figure 1). Professional codes teach students their professional engineering responsibilities (knowledge of ethics), and case studies allow students to explore possibilities, options, and alternatives in order to determine a course of action (ethical reasoning). Finally, service learning and other experiential education offer a context to encounter ethical issues and practice behaving ethically (ethical behavior).

Recommendation 2: Collaborate across disciplines and divisions to create content around ethics education

Participants reported that collaborating with faculty in other departments (e.g., philosophy, psychology) to create courses, modules, or guest lectures to address the topic of ethics was a useful approach. This collaboration allowed engineering faculty to glean knowledge from "trained ethicists," while also ensuring the material was specific to the engineering profession. For example, one institution had an ethics institute on campus and the Dean of Engineering supported summer workshops for faculty to receive help integrating ethics into the curriculum, as the academic affairs administrator described:

[The dean] supported workshops in the summer for faculty in much the same way that, if they had research, he would support their time...Each department was to submit one or two faculty members' projects ...They would come to the workshops, they'd work, they'd get an assignment, they'd go back and work on their syllabus and assessment method...so, you know, they'd figure out how to do this and they had to present to the class. And so, through that summer, through a series of various workshops, they developed materials and assessment methods within their courses, not only to include [ethics] but to include it in meaningful ways and then to evaluate whether or not the students were getting it. 
The collaboration with members of the ethics institute addressed the perceived lack of ethics training. The ethicists not only helped faculty incorporate ethics into their existing courses in a meaningful and measurable way, but also gave engineering faculty the support and confidence to teach ethics.

This particular campus was fortunate to have a centralized ethics institute which made collaboration easy. Participants from other campuses indicated they partnered with individual professors in philosophy to create courses or course content, and still others sought advice from professors of business or medical ethics on how to incorporate ethics into their courses. Teaching and learning centers on campus also offered guidance on new ways to approach teaching ethics.

Recommendation 3: Offer incentives to faculty for training or curricular innovation

One way to encourage faculty to overcome the other obstacles to incorporating ethics into the curriculum is to offer incentives to faculty for training or curricular innovation. By giving faculty release from teaching, summer support, or professional development funds, faculty will have time and money to invest in modifying their courses to include ethics education. As the above example of collaboration notes, the dean supported using time for research and time for faculty training for ethics equally, and faculty were therefore able to take advantage of the summer workshops.

Incentives for training or curricular innovation can also be worked into the promotion and tenure process. Faculty could be rewarded for trying innovative teaching methods or restructuring courses and assessing these changes, independent of the student evaluation process. As the administrator above noted, faculty may be reluctant to try new pedagogy because they fear the negative student evaluation. However, separating curricular innovation and student evaluations in promotion and tenure allows faculty to push students beyond what is comfortable to consider ethical issues.

Incentives also indicate the significance and value that the administration places on incorporating ethics into the curriculum. By offering incentives (e.g., release from teaching, additional money for training), the administration sends a message that ethics are not only an important part of the curriculum, but also an important part of faculty development and institutional culture.

Recommendation 4: Present consistent policies among faculty and staff regarding academic dishonesty

Consistent policies about academic policy are needed both in terms of the policies themselves and the enforcement of the policies. For the faculty member who worked at the satellite campus, the lack of honor code led to confusion for both faculty and students as they tried to navigate the inconsistencies and decide how to handle issues of academic dishonesty. In addition, inconsistencies among faculty about how to handle instances of cheating can also create mixed messages about the severity of academic dishonesty. Consistent policies and consistent enforcement eliminate the mixed messages and establish a cultural norm of ethical behavior in the classroom.

Differences among faculty about how students work in groups or complete homework assignments can create "mixed messages" about what is considered cheating. Students who are 
encouraged to teach each other in one class, but told to work alone in another often struggle to understand why one professor allows collaboration and another does not. In addition to group work, some faculty encouraged the use of solutions manuals as a teaching tool, while others viewed solutions manuals as cheating. These inconsistencies create confusion because the students are unsure about what constitutes cheating. In these situations, consistency among faculty may alleviate confusion among students, but it is probably not realistic to expect professors to agree about how to handle individual course assignments. Rather, faculty should discuss their policies and be able to consistently provide their rationale for homework and collaboration to other faculty and to students. If a professor understands why he or she has chosen to structure assignments in a particular way, that professor can then help the students understand and thus navigate the differences among faculty and courses more effectively. In addition, discussing these classroom policies with students offers an added benefit of engaging students in ethical conversations to promote ethical development.

Institutions offered several ways to establish and communicate policies to faculty and students. Faculty often included academic integrity statements in their syllabi, and these statements can be shared with other faculty in the department or written in collaboration with other faculty members so that expectations for academic honesty are clear and consistent for both faculty and students. In addition, many institutions included presentations or discussions about the honor code or academic honesty in orientation sessions to ensure all students received consistent messages upon entrance to the university. Sponsored programs for faculty and students also offer opportunities to discuss issues of academic integrity in a public forum.

Institutions also used different methods to enforce honor codes or academic policies. Several institutions established a single department or individual to handle violations, and faculty referred cases to that department or person. By referring cases to a single entity, the administrator can investigate the incident and keep records to determine whether the student has a history or pattern of academic misconduct without burdening the professor. However, if the student was found responsible for violating an academic policy, this finding was communicated to the professor, and the impact on the student's grade was often left to the discretion of the individual professor. This method allowed professors the opportunity to discuss the incident with the student, and offered another setting for a "teachable moment" through an ethical conversation.

\section{Discussion}

The Input-Environment-Output model ${ }^{2}$ offers a framework that is helpful for assessing ethical development, and it also offers a context to examine environmental factors affecting development. We investigated the institutional obstacles to integrating ethics in the curriculum, which highlights the relationship between the "Institutional Culture" and "Formal Curricular Experiences" components of our model (Figure 1). In this study, elements of institutional culture interfered with the delivery of ethical material in formal curricular experiences which can ultimately have a negative impact on development. When the ethical curriculum is limited, the benefit to students is also limited.

We can also examine the environmental components of the model to find solutions for overcoming the institutional barriers. In contrast to the interfering obstacles found in the 
relationship between institutional culture and formal curricular experiences, integration and collaboration among environmental components serves as a way to overcome the institutional barriers. For example, the recommendation to integrate "Formal Curricular Experiences" and "Co-Curricular Experiences" also examines the relationship between two environmental components. In this relationship, the partnership serves as a way to circumvent the institutional barrier, particularly the overburdened curriculum. Rather than adding or removing coursework or changing policies around degree requirements, the integration of curricular and co-curricular experiences allows faculty to utilize an existing component of the college environment and the student experience to teach ethics. Case studies, professional codes of ethics, and experiential learning are all recommended methods for teaching ethics and promoting ethical behavior $^{3,7,8,9,10,11}$, and participants provided many examples of ways in which co-curricular experiences used these methods to teach ethics.

Though attempts to work around challenges can be productive, sometimes the only way to overcome an environmental obstacle is to remove the obstacle. Collaborating with other departments to create ethics modules uses the existing campus resources to overcome the lack of training and the insecurities about teaching unfamiliar material. In addition, training faculty to teach ethics and offering incentives to incorporate ethics into coursework demonstrates a commitment to ethics as an integral part of engineering education and therefore an integral part of the institutional culture. Incentivizing and placing value on the integration of ethics into the curriculum shifts the institutional culture towards a culture of ethical development, thereby minimizing an obstacle to integrating ethics into the curriculum. Hopefully, this shift changes the relationship between environmental components from that of interference to that of facilitation so that the curriculum then reflects the institutional value placed on ethics and ethical development. Valuing ethics and making ethics an integral part of institutional culture will likely promote ethical development among engineering undergraduates.

\section{Conclusions}

Each institution in our study identified obstacles toward incorporating ethics into the curriculum, and many also offered suggestions for overcoming these barriers. Whether finding room in the curriculum to teach ethics or considering inconsistencies in academic policies, discussions about ethics and the role ethics plays in the institution is the first step to overcoming any obstacles. Future research should investigate barriers to ethical development found in other environmental components (e.g., curricular experiences, co-curricular experiences) and student characteristics, and offer strategies for overcoming those barriers. In addition, future research should explore student perceptions of ethics in the curriculum, as well as best practices for teaching ethics in the engineering undergraduate curriculum using both qualitative and quantitative methods.

\section{Acknowledgements}

This work was supported in part by grants from the National Science Foundation (EEC\# 0647460, 0647532, and 0647929). The views expressed represent those of the authors and not necessarily those of the National Science Foundation. 


\section{Bibliography}

1. American Society of Civil Engineers (2009). Code of ethics. Retrieved December 23, 2009 from https://www.asce.org/inside/codeofethics.cfm

2. Astin, A. W. (1993). Assessment for excellence: The philosophy and practice of assessment and evaluation in higher education. Phoenix, AZ: The Oryx Press.

3. Bebeau, M. J., \& Thoma, S. J. (1999). "Intermediate" concepts and the connection to moral education. Educational Psychological Review, 11(4), 343-360.

4. Corbin, J., \& Strauss, A. (2008). Basics of qualitative research: Techniques and procedures for developing grounded theory (3rd ed.). Thousand Oaks, CA: Sage Publications, Inc.

5. Engineering Accreditation Commission (2007). Criteria for accrediting engineering programs: Effective for evaluations during the 2008-2009 accreditation cycle. Retrieved December 16, 2009, from Accreditation Board for Engineering and Technology website:http://www.abet.org/forms.shtml\#For_Engineering_Programs_Only

6. Gibbons, M. T. (2009). Engineering by the numbers. Retrieved March 17, 2010 from http://www.asee.org/publications/profiles/upload/2008ProfileEng.pdf

7. Harris, C. G., Davis, M., Pritchard, M., and Rabins, M. J. (1996). Engineering ethics: What? Why? How? And when? Journal of Engineering Education, 85(2), 93-96.

8. Haws, D. R. (2001). Ethics instruction in engineering education: A (mini) meta-analysis. Journal of Engineering Education, 90(2), 223-229.

9. Herkert, J. R. (2000). Engineering ethics education in the USA: Content, pedagogy, and curriculum. International Journal of Engineering Education, 25(4), 303-313.

10. Herkert, J. R. (2003). Microethics, macroethics, and professional engineering societies. Emerging technologies and ethical issues in engineering (pp. 107-166). Washington, DC: National Academy Press.

11. Kline, Ronald R. (2001/2002) Using History and Sociology to Teach Engineering Ethics. IEEE Technology and Society Magazine, 20(4): 13-20.

12. National Academy of Engineering. (2003). Emerging technologies and ethical issues in engineering. Washington, DC: National Academy Press.

13. National Academy of Engineering. (2004). The engineer of 2020: Visions of engineering in the new century. Washington, DC: National Academy Press.

14. National Society of Professional Engineers (2009). NSPE code of ethics for engineers. Retrieved December 23, 2009 from http://www.nspe.org/Ethics/CodeofEthics/index.html

15. Newberry, B. (2004). The dilemma of ethics in engineering education. Science and Engineering Ethics, 10(2), 343-351.

16. For a full description of the protocol development, see Sutkus, J., Carpenter, D., Finelli, C., Harding, T. (2008). Work in progress: Building the Survey of Engineering Ethical Development (SEED) instrument. Proceedings of the 38th Frontiers in Education Conference, Sarasota Springs, NY. (IEEE Catalog Number: CFP08FIE-CDR) 